\title{
CONSERVAS EM SALMOURAS OU ÁCIDAS DE VEGETAIS TIPICAMENTE BRASILEIROS: REVISÃO DA LITERATURA
}

\section{ARTIGO DE REVISÃO}

JULIÃO, Murilo Sérgio da Silva ${ }^{1}$

NETO, Leopoldo Gondim ${ }^{2}$

AMARAL, Rafael Queiroz Gurgel do ${ }^{3}$

JULIÃO, Murilo Sérgio da Silva. NETO, Leopoldo Gondim. AMARAL, Rafael Queiroz Gurgel do. Conservas em salmouras ou ácidas de vegetais tipicamente brasileiros: Revisão da literatura. Revista Científica Multidisciplinar Núcleo do Conhecimento. Ano 04, Ed. 10, Vol. 09, pp. 23-40. Outubro de 2019. ISSN: 24480959 , Link de acesso: https://www.nucleodoconhecimento.com.br/gastronomia/conservas-emsalmouras

\section{RESUMO}

Os frutos e hortaliças oriundos da rica flora brasileira tem um grande potencial a ser explorado quando associados aos métodos tradicionais de conservação de alimentos. Entretanto, poucas variedades de vegetais da biodiversidade brasileira vêm sendo aproveitadas com esta finalidade. Esta revisão buscou identificar na literatura, vegetais tipicamente brasileiros que apresentaram potencialidades para serem processados sob a forma de conservas salgadas e/ou acidificadas. Para a pesquisa bibliográfica, foram utilizadas ferramentas de busca de dados em três bases: Scielo,

\footnotetext{
${ }^{1}$ Discente do Curso de Gastronomia do Instituto de Cultura e Arte (ICA) - UFC. Doutor em Química Analítica pelo Instituto de Química - USP.

${ }^{2}$ Mestre em Educação Brasileira pela Faculdade de Educação - UFC.

${ }^{3}$ Gastrônomo pelo Centro Universitário SENAC de Campos de Jordão.
} 
Lilacs e Web of Science. Os dados coletados foram apresentados em formato de tabela e algumas informações importantes podem ser extraídas: grande variedade de vegetais disponíveis em cada região, pouca informação publicada na literatura especializada sobre preparações em forma de conservas, a maioria dos alimentos em conserva como picles ou chutney são processados com plantas exóticas, embora, alguns vegetais tipicamente brasileiros têm sido utilizados para essa finalidade, a maioria apresenta algumas desvantagens ao serem conservados em salmouras e/ou em ácidos, como: diminuição dos atributos sensoriais, de nutrientes, instabilidade física em solução, etc. Portanto, foi observado por meio da análise dos artigos que nem sempre a viabilidade em conservar vegetais, provenientes de biomas brasileiros, sob a forma de salmouras e/ou ácidos, a fim de valorizar os alimentos regionais, implica na aceitação sensorial pelos consumidores.

Palavras-chave: Cozinha fria, flora brasileira, gastronomia, salga úmida.

\section{INTRODUÇÃO}

A partir do momento que a humanidade desenvolveu a capacidade de acumular alimentos com a práticas agrícolas, passou a enfrentar um problema, como preserválos por um longo tempo sem que fossem degradados e que pudessem ser consumidos futuramente. Durante vários séculos, a conservação dos alimentos ficou restrita aos métodos de secagem ao sol, à defumação à salga e aos usos do açúcar e do vinagre. Entretanto, esses métodos geralmente implicavam na perda ou alteração dos sabores originais dos alimentos, além da diminuição nutricional dos alimentos.

No século II a.C., os romanos salgavam as verduras com a intenção de neutralizar seu amargor natural, daí deriva a palavra salada. Nesta época, para saber se a salmoura tinha sal suficiente para ser usada em conservas, o escritor latino Catão sugeriu em seu livro "De agricultura", que se mergulhasse uma anchova ou um ovo na salmoura (KURLANSKY, 2003).

Em “De caçador a gourmet: uma história da gastronomia”, Ariovaldo (2001) relata que: 
[...] Napoleão ofereceu um prêmio vultuoso para quem inventasse um processo para conservar mantimentos por longo período. O prêmio coube a Nicolas Appert, autor do livro L'Art de conserver les susbtances animales et végétales, após demonstrar que alimentos fervidos em recipientes de vidro e, em seguida, fechados hermeticamente se conservavam por meses [...] (ARIOVALDO, p. 218, 2001).

Ao longo do século XX, a conservação dos alimentos foi sendo melhorada sob a ótica da Ciência \& Tecnologia, utilizando para isto vários métodos de conservação, dentre os quais Sebess (2014) cita alguns:

A conserva serve para preservar alimentos durante um período de tempo mais prolongado, utilizando diversos métodos, como os térmicos (esterilização, pasteurização, refrigeração e congelamento), os métodos de redução de água (salga, adição de açúcar para as conservas em caldas, desidratação, concentração por evaporação e por liofilização para preparação de sucos), os métodos de aumento da acidez (com adição de vinagres), os métodos de redução de oxigênio (embalagem à vácuo) e os que utilizam substâncias inibidoras (conservantes como o álcool para produção de licores e frutas em álcool). Dessa maneira é possível consumir produtos sazonais em todas as épocas do ano (SEBESS, p. 338, 2014).

Assim, a conservação dos alimentos via métodos tradicionais surgiu como uma alternativa inteligente para que se mantivessem próprios para o consumo humano por um tempo mais longo, numa época em que não havia geladeiras e/ou freezers. Posteriormente, essa alternativa buscou disponibilizar as matérias-primas sazonais durante todos os dias do ano. Em resumo, o termo conservas hoje em dia é mais utilizado para designar inúmeros tipos de alimentos submetidos a procedimentos caseiros ou industriais com a finalidade de aumentar a vida útil de prateleira deles, tornando possível o consumo fora da época de safra desses alimentos, longe dos locais produtores, ou prontos a serem consumidos.

Atualmente, o profissional da Cozinha Fria quase não utiliza mais os métodos tradicionais de conservação, pois existem tecnologias avançadas para conservar os alimentos, ao contrário, utiliza alimentos curados, defumados e conservas em salmoura disponíveis comercialmente com a finalidade de permitir que os sabores desses alimentos possam ser apreciados pelos paladares das pessoas. 


\subsection{CONSERVAS EM SALGA ÚMIDA E/OU ACIDIFICADA}

Existem vários tipos de insumos que podem ser utilizados em conservas: frutas, hortaliças, condimentos, carnes, pescados, frutos do mar, palmitos, champignons, ovos, dentre outros. As conservas podem ter inúmeras apresentações como: doces, salgadas e/ou ácidas. As conservas doces basicamente são produzidas a partir de frutas e açúcar. As salgadas e/ou ácidas podem ser produzidas utilizando-se como base para sua conservação a salmoura, o vinagre, o vinho ou o óleo comestível, sendo mais usado 0 azeite (SEBESS, 2014).

As conservas em salga úmida ou acidificadas servem para despertar as papilas gustativas, razão pela qual é tão prazeroso prepará-las. Esses tipos de conservas são bastante versáteis e simples de fazer. Historicamente, o sal (cloreto de sódico), o vinagre e açúcar são os agentes conservantes mais tradicionais. O sal de cozinha, quando utilizado em soluções concentradas (salmoura) é o conservante mais importante, pois atua na retirada da umidade do alimento impedindo a proliferação de microrganismos. O vinagre contém no mínimo $5 \%$ de ácido acético e por isto, apresenta eficiência na inibição do crescimento de microrganismos, incluindo a $E$. coli, que geralmente estraga os alimentos. Essa solução ácida é muito utilizada na preparação de picles, relishes e molhos; e quando combinada ao açúcar produz uma harmonia apropriada para a produção de chutneys.

\subsubsection{PICLES}

Picles é um tipo de conserva preparada com as partes comestíveis de frutas, legumes e hortaliças, conservadas em salmoura ou em vinagre, com ou sem fermentação lática, podendo também conter, açúcar ou especiarias e são divididos em duas categorias: os picles em salmoura (fermentados e não fermentados) e os picles em vinagre (ácidos, doces e aromatizados) (BENEVIDES; FURTUNATO, 1998) e para que o procedimento de acidificação seja bem sucedido $\circ \mathrm{pH}$ do picles deve ficar abaixo de 4,5 (RAUPP et al., 2008). 
A preparação e comercialização de picles, no Brasil, devem seguir as regulamentações da Agência Nacional de Vigilância Sanitária (ANVISA). Esta informa que os produtos em conserva logo após seu envasamento devem ser sujeitados e adequados a procedimentos tecnológicos antes e depois das embalagens serem fechadas hermeticamente, para que não haja nenhum tipo de modificação em sua composição. Porém, em alimentos onde o pH do meio é inferior a 4,5, pode-se usar a pasteurização a fim de inibir o desenvolvimento de quaisquer microrganismos (BRASIL, 2005).

Hoje em dia, preparam-se picles muito mais pela questão do sabor do que pela preservação dos alimentos, uma vez que essa conserva confere um sabor agridoce acentuado. O modo mais simples de preparar picles é fazer uma salmoura e adicionar vegetais crus ou cozidos. Geralmente uma salmoura é feita com 1 parte de sal para 8 partes de água, porém alguns outros ingredientes podem ser acrescentados para dar mais sabor, como açúcar, condimentos, ervas e pimentas. A maioria dos trabalhos da literatura publicados sobre conservas de vegetais em salmoura ou ácidos ainda é restrita aos tipos mais comuns como: pepino japonês (Cucumis sativus L.), cebola pera (Allium cepa L.), cenoura (Daucus carota L.), couve-flor (Brassica oleracea), pimentões verde ou amarelo (Capsicum annum L.) (BENEVIDES; FURTUNATO, 1998); rabanete (Raphanus sativus L.) (PIZZATTO; LUCKMANN; MOURA et al., 2011); chuchu (Sechium edule (Jacq.) Swartz), vagem (Phaseolus vulgaris) e repolho (Brassica oleracea) (BENEVIDES; FURTUNATO, 1998 apud GOLDONI et al., 1988), ou seja, vegetais com consistência firme, pois suportam melhor esse tipo de preparação.

\subsubsection{CHUTNEY}

A palavra inglesa chutney (originária do hindu chatni) é utilizada para designar um tipo de conserva picante de origem indiana, na qual vegetais e/ou frutas são cozidos junto com especiarias, vinagre e açúcar. Na preparação da receita original de chutney são utilizados vinagre, maçã, açúcar mascavo e sal. Genericamente, chutney é um condimento composto por doce (derivado das frutas), ácido (fornecido pelo limão ou vinagre), legumes e especiarias (RIBEIRO et al., 2013). Geralmente é servido na 
forma de uma pasta ou molho salgado para acompanhar carnes assadas ou grelhadas.

Segundo Madakadze et al., (2004), o alto nível de açúcares presentes no molho possui um efeito conservante não sendo sempre necessária a adição de vinagre, mas isso depende diretamente da acidez e maturação natural dos frutos usados na preparação. Após aberto o frasco de chutney é conservado pelos ácidos naturais da fruta, do vinagre e os produtos resultantes do processo de fermentação, juntamente com o alto teor de açúcar. A técnica utilizada para a preparação de chutney é simples, variando apenas a introdução de ingredientes em distintos tempos de cozimento, assim como, a obtenção de variadas características químicas do produto final como: acidez, pH e grau Brix. Em termos econômicos, a produção de chutney possibilita o aproveitamento de hortaliças e frutas que por algum motivo não puderam ser comercializadas a fresco. (RIBEIRO et al. 2013.).

Entretanto, a biodiversidade brasileira apresenta um grande potencial de vegetais propícios para a preparação de conservas, em especial às obtidas a partir de legumes e hortaliças nativas ou adaptadas à flora brasileira. Portanto, este trabalho apresenta uma breve revisão da literatura sobre as conservas em salmoura (picles) ou ácidas (chutney) produzidas com vegetais e frutas da flora brasileira.

\section{METODOLOGIA}

Esta revisão é baseada num delineamento transversal com coleta de dados por meio de pesquisas bibliográfica e online. Inicialmente, foram utilizadas fontes bibliográficas para pesquisa: de picles; ou conservas em salmoura; ou conservas em ácidos de vegetais tipicamente brasileiros.

Como a literatura ainda está incipiente de livros especializados em conservas processadas com vegetais obtidas da flora brasileira, a pesquisa bibliográfica se restringiu à busca por artigos nas seguintes bases de dados: Web of Science, Lilacs e Scielo utilizando os unitermos "picles" ou "chutney" ou "conservas ácidas" ou "salmouras" ou "flora brasileira" ou "vegetais brasileiros" ou "hortaliças brasileiras". 
A coleta dos dados foi realizada no período entre 25 de janeiro e 24 de julho de 2019 , através de um site de buscas com utilização dos mesmos unitermos mencionados acima. Os dados coletados foram resumidos e apresentados em forma de tabelas.

\section{RESULTADOS E DISCUSSÃO}

Os primeiros trabalhos científicos reportando o uso de insumos alimentícios tipicamente brasileiros na preparação de conservas em salmoura e/ou ácidas foram publicados no início da década de 1990, porém a maioria versava sobre alimentos originários da fauna brasileira. Carvalho \& Lessi (1990), iniciaram uma série de estudos sobre as condições corretas de combinação de tempo de cura, acidificação e nível de sal para produção de semiconservas de pescados de água doce acondicionadas em vidro. Esses autores verificaram que os peixes como: 0 jaraqui (Semaprochilodus spp.), o curimatã (Prochilodus nigricas), 0 dourado (Brachyplastistoma favlicans) e o pirarucu (Arapaima gigas) apresentaram textura e sabor agradáveis após 4 semanas de cura, pH em torno de 4,5 e 15\% (m/v) de sal na salmoura.

Porém, somente uma década após a publicação dessa série de artigos é que as primeiras pesquisas envolvendo a utilização e/ou aplicação de vegetais tipicamente brasileiros em conservas salgadas e/ou ácidas foram disponibilizadas para a comunidade científica e público em geral. Em 1999, Barcelos; Tavares; Silva e colaboradores tentaram viabilizar a venda comercial do guandu [Cajanus cajan (L.) Mill sp.] verde enlatado no mercado brasileiro, mas apesar de terem observado as melhores características físico-químicas para o enlatamento desse grão, a aceitação sensorial do guandu enlatado foi apenas regular (BARCELOS; TAVARES; SILVA et al., 1999).

Visando tornar possível o aproveitamento do xilopódio de umbuzeiro (Spondias tuberosa) como alternativa alimentar e fonte de complementação da renda dos pequenos agricultores da região semiárida do Nordeste brasileiro, Cavalcanti e colaboradores (2001) produziram e testaram a aceitação sensorial de três formas de picles feitas com o xilopódio de plantas de umbuzeiro. Foi observado que o picles 
processado com salmoura de 2,5\% de sal comum e 0,5\% de ácido ascórbico foi o preferido pelos provadores, porém o xilopódio in natura não obteve boa aceitação quanto à textura, pois nesta forma de apresentação a consistência do xilopódio não permite uma boa mastigação. (CAVALCANTI; SANTOS; REZENDE et al. 2001).

A Tabela 1 apresenta um resumo das motivações e dificuldades para a utilização de vegetais da flora brasileira na preparação de conservas em salmoura (picles) publicadas na literatura especializada.

Tabela 1 - Vegetais da flora brasileira utilizados na preparação de conservas em salmoura (picles).

\begin{tabular}{|c|c|c|c|}
\hline $\begin{array}{l}\text { Insumo utilizado na } \\
\text { produção de picles }\end{array}$ & Motivações & Dificuldades & Referências \\
\hline $\begin{array}{l}\text { Feijão caupi verde } \\
\text { [Vigna unguiculata (L.) } \\
\text { Walp.]. Objetivo: } \\
\text { Introduzir } 10 \text { linhagens } \\
\text { e } 2 \text { cultivares para } \\
\text { processamento tipo } \\
\text { conserva. }\end{array}$ & $\begin{array}{l}\text { O feijão caupi verde não } \\
\text { sofre grandes alterações } \\
\text { e mantem suas boas } \\
\text { características na } \\
\text { obtenção das conservas. }\end{array}$ & $\begin{array}{l}\text { Perda parcial } \\
\text { de proteína } \\
\text { total dos } \\
\text { grãos. }\end{array}$ & $\begin{array}{l}\text { Lima; } \\
\text { Jerônimo; } \\
\text { Lima et al., } \\
2003 .\end{array}$ \\
\hline $\begin{array}{l}\text { Palmito de pupunheira } \\
\text { (Bactris gasipaes). } \\
\text { Objetivo: Avaliar o } \\
\text { efeito de três } \\
\text { salmouras (3,5\%, 4,0\% } \\
\text { ou 4,5\%, m/v, de sal) no } \\
\text { paladar dos palmitos } \\
\text { pupunha tolete e basal } \\
\text { para aplicação na } \\
\text { agroindústria. }\end{array}$ & $\begin{array}{l}\text { As conservas de palmito } \\
\text { tolete contendo } \\
\text { salmouras de } 3,5 \% \text { ou } \\
4,0 \% \text { em sal tiveram a } \\
\text { preferência } \\
\text { degustadores para o } \\
\text { atributo sensorial "gosto } \\
\text { de palmito". Já, para a } \\
\text { conserva de palmito } \\
\text { basal os provadores } \\
\text { apreciaram igualmente }\end{array}$ & & $\begin{array}{l}\text { Raupp; } \\
\text { Almeida; } \\
\text { Staron et al., } \\
2004 \text {. }\end{array}$ \\
\hline
\end{tabular}




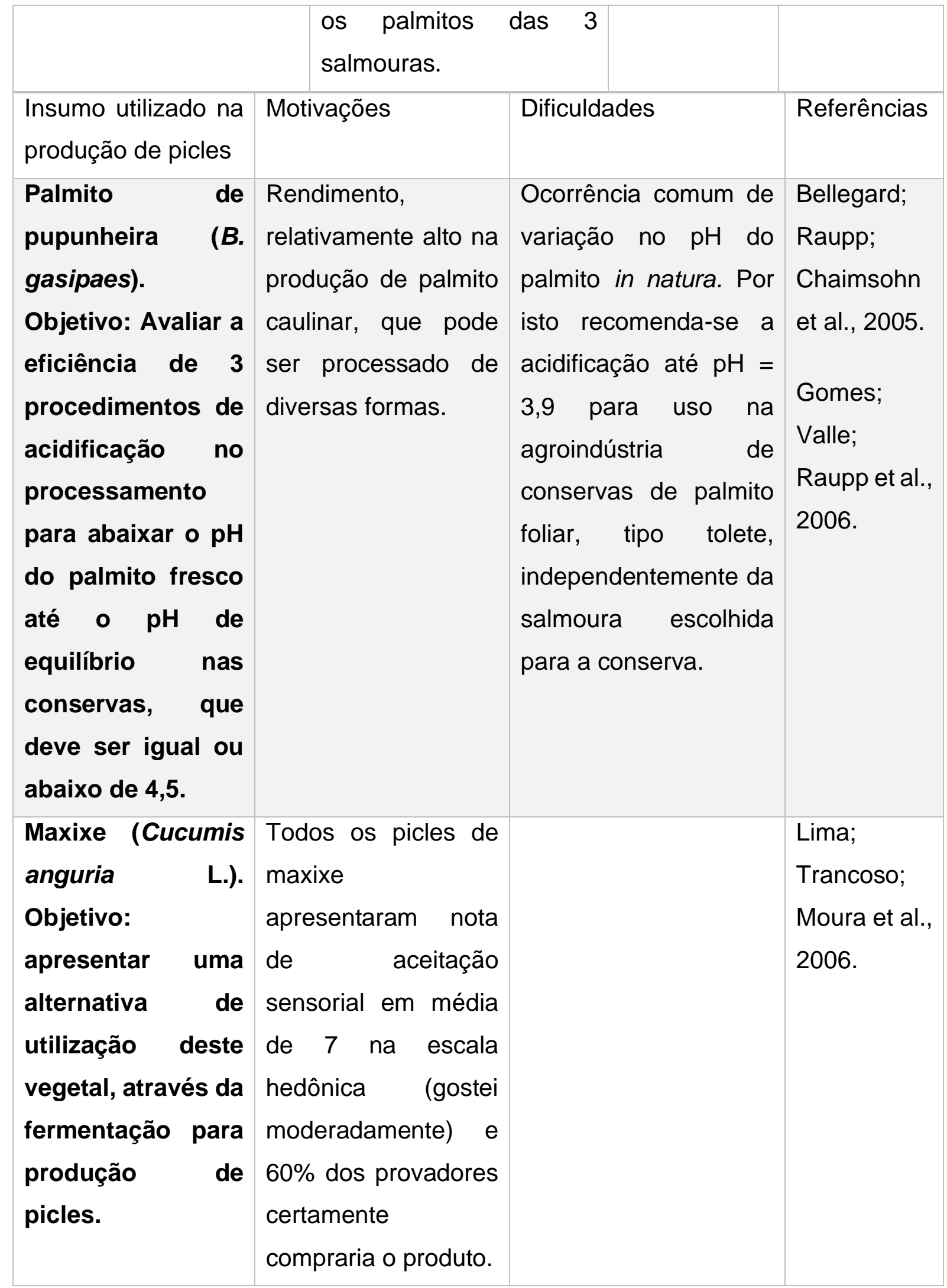




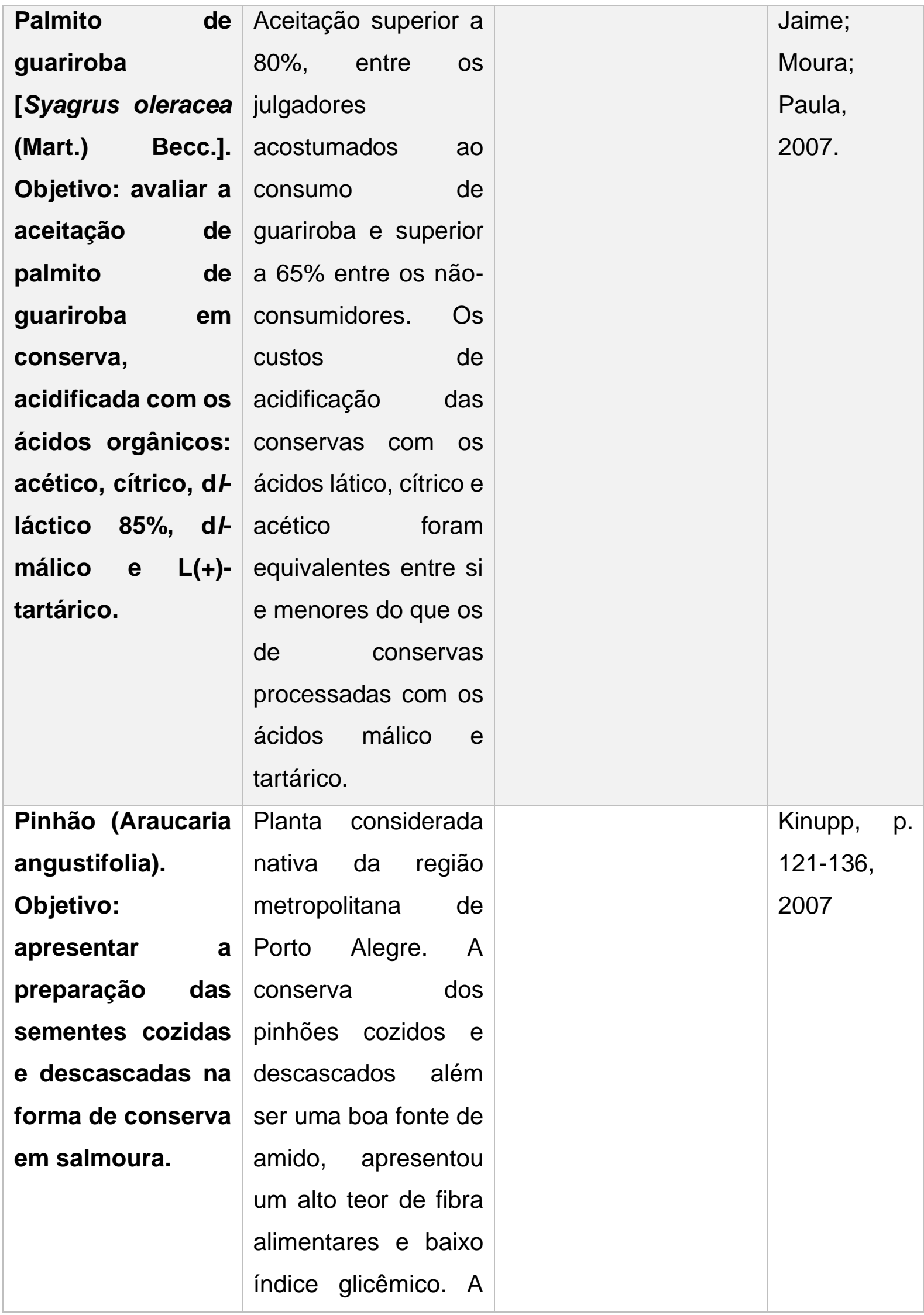


conserva

das

sementes de pinhão

já é bastante

comercializada na

região Sul do Brasil.

\begin{tabular}{|c|c|c|c|}
\hline $\begin{array}{l}\text { Insumo utilizado na } \\
\text { produção de picles }\end{array}$ & Motivações & Dificuldades & Referências \\
\hline $\begin{array}{l}\text { Jurubeba- } \\
\text { verdadeira } \\
\text { (Solanum } \\
\text { paniculatum L.). } \\
\text { Objetivo: } \\
\text { apresentar } \\
\text { processamento } \\
\text { dos frutos na forma } \\
\text { de conserva } \\
\text { (picles). }\end{array}$ & $\begin{array}{l}\text { Planta amplamente } \\
\text { difundida em todas as } \\
\text { regiões brasileiras e } \\
\text { por isto, os frutos de } \\
\text { jurubeba-verdadeira } \\
\text { são amplamente } \\
\text { comercializados em } \\
\text { restaurantes regionais } \\
\text { de Goiás, Mato Grosso } \\
\text { do Sul e Minas Gerais, } \\
\text { tanto in natura como } \\
\text { em conserva. }\end{array}$ & $\begin{array}{l}\text { Não há estudo } \\
\text { bromatológico } \\
\text { sobre os frutos de } \\
\text { jurubeba- } \\
\text { verdadeira. }\end{array}$ & $\begin{array}{l}\text { Kinupp, } 361- \\
362,2007 .\end{array}$ \\
\hline $\begin{array}{l}\text { Pepinhos-de-purga } \\
\text { (Melothria } \\
\text { cucumis). Objetivo: } \\
\text { fazer análise } \\
\text { sensorial dos } \\
\text { frutos in natura e } \\
\text { em conserva desta } \\
\text { PANC. }\end{array}$ & $\begin{array}{l}\text { Picles de pepininhos- } \\
\text { de-purga apresentou } \\
\text { um sabor suave } \\
\text { quando comparado ao } \\
\text { pepino convencional } \\
\text { (Cucumis sativus). } \\
\text { Crocância provocada } \\
\text { pelas sementes } \\
\text { durante a mastigação. }\end{array}$ & $\begin{array}{l}\text { Teve uma } \\
\text { aceitação } \\
\text { indiferente, menor } \\
\text { do que a do pepino } \\
\text { (Cucumis sativus) } \\
\text { tipo indústria. }\end{array}$ & $\begin{array}{l}\text { Kinupp, } \\
482-515 \\
2007 .\end{array}$ \\
\hline $\begin{array}{l}\text { Palmito de jerivá } \\
\text { (Syagrus } \\
\text { romanzoffiana). }\end{array}$ & $\begin{array}{l}\text { Procedimento de } \\
\text { acidificação projetado } \\
\text { para o processamento }\end{array}$ & $\begin{array}{l}\text { Nutricionalmente, o } \\
\text { palmito jerivá em } \\
\text { conserva } \quad \text { se }\end{array}$ & $\begin{array}{l}\text { Raupp; } \\
\text { Kulchetski; }\end{array}$ \\
\hline
\end{tabular}




\begin{tabular}{|c|c|c|c|}
\hline $\begin{array}{lr}\text { Objetivo: } & \\
\text { caracterizar } & \text { o } \\
\text { processo } & \text { de } \\
\text { produção } & \text { da } \\
\text { conserva } & \text { de } \\
\text { palmito de jerivá e } \\
\text { determinar } \\
\text { características } \\
\text { desse produto. }\end{array}$ & $\begin{array}{l}\text { de conservas de } \\
\text { palmito mostrou ser } \\
\text { eficiente para a } \\
\text { produção de conservas } \\
\text { seguras, de acordo } \\
\text { com a norma oficial, } \\
\text { para o consumo na } \\
\text { alimentação humana. } \\
\text { O palmito da conserva } \\
\text { apresenta sensação } \\
\text { adstringente durante } \\
\text { sua permanência na } \\
\text { boca e por isto foi } \\
\text { considerado um } \\
\text { produto exótico para } \\
\text { ser consumido em } \\
\text { ocasiões especiais. }\end{array}$ & $\begin{array}{l}\text { caracteriza como } \\
\text { um alimento de } \\
\text { baixa caloria e } \\
\text { fibroso. }\end{array}$ & $\begin{array}{l}\text { Bosmuler, } \\
2007 .\end{array}$ \\
\hline $\begin{array}{l}\text { Maxixe (C. anguria } \\
\text { L.) Objetivo: } \\
\text { elaborar uma } \\
\text { conserva } \\
\text { acidificada } \\
\text { artificialmente e } \\
\text { testar a } \\
\text { estabilidade } \\
\text { química, bem como } \\
\text { a aceitação por } \\
\text { parte dos } \\
\text { consumidores. }\end{array}$ & $\begin{array}{l}\text { Apresenta valores de } \\
\mathrm{pH} \text { abaixo de } 4,5 \text {, } \\
\text { portanto pode ser } \\
\text { considerado parâmetro. } \\
\text { produto seguro, para } \\
\text { este um } \\
\text { Sensorialmente é um } \\
\text { produto bem aceito. } \\
\text { Além disso, o maxixe } \\
\text { em conserva } \\
\text { apresenta abertura de } \\
\text { mercado para a } \\
\text { produção em escala } \\
\text { industrial. }\end{array}$ & & $\begin{array}{l}\text { Nascimento; } \\
\text { Nunes; } \\
\text { Nunes, } \\
2011 .\end{array}$ \\
\hline
\end{tabular}




\begin{tabular}{|c|c|c|c|}
\hline $\begin{array}{l}\text { Insumo utilizado na } \\
\text { produção de picles }\end{array}$ & Motivações & Dificuldades & Referências \\
\hline $\begin{array}{l}\text { Hortaliças regionais } \\
\text { amazônicas: feijão-de- } \\
\text { praia ( } V \text {. unguiculata } \\
\text { (L.); abóbora (Cucubita } \\
\text { moschata), macaxeira } \\
\text { (Manihot esculeta } \\
\text { Crantz), maxixe ( } C \text {. } \\
\text { anguria L.) e palmito ( } B . \\
\text { gasipaes } K \text {.). Objetivo: } \\
\text { avaliar a qualidade, } \\
\text { aceitabilidade } \\
\text { viabilidade comercial } \\
\text { da salada em conserva } \\
\text { acidificada elaborada } \\
\text { com abóbora, feijão de } \\
\text { praia, macaxeira, } \\
\text { maxixe e palmito de } \\
\text { pupunheira }\end{array}$ & $\begin{array}{l}\text { Produto de pouco valor } \\
\text { calórico, seguro para o } \\
\text { consumo e que não } \\
\text { apresenta perdas } \\
\text { significativas dos } \\
\text { constituintes nutricionais. } \\
\text { Atende aos padrões físico- } \\
\text { químicos } \\
\text { microbiológicos exigidos } \\
\text { pela legislação brasileira. } \\
\text { Apresentou boa aceitação } \\
\text { e variáveis de qualidade } \\
\text { sensorial semelhantes às } \\
\text { do produto industrializado } \\
\text { e } \\
\text { nacionalmente. O produto } \\
\text { obtido demonstrou ser } \\
\text { competitivo } \\
\text { economicamente viável. }\end{array}$ & & $\begin{array}{l}\text { Araújo; } \\
\text { Chaar; } \\
\text { Marques, } \\
2014 .\end{array}$ \\
\hline $\begin{array}{l}\text { Palmas "doce" } \\
\text { (Nopalea } \\
\text { cochenilifera), } \\
\text { "redonda" (Opuntia sp) } \\
\text { e "graúda" (Opuntia } \\
\text { fícus indica Mill) } \\
\text { produzidas na região } \\
\text { do Curimataú } \\
\text { Paraibano. Objetivo: } \\
\text { avaliar as }\end{array}$ & $\begin{array}{l}\text { Os picles produzidos com } \\
\text { a polpa dos troncos das } \\
\text { três variedades de palma } \\
\text { apresentaram no conjunto } \\
\text { das análises sensoriais, } \\
\text { evidências de um alto grau } \\
\text { de aceitação e potencial } \\
\text { de sua comercialização. }\end{array}$ & & $\begin{array}{l}\text { Morais } \\
\text { Júnior; } \\
\text { Laime; } \\
\text { Oliveira } \\
\text { al., } 2014 .\end{array}$ \\
\hline
\end{tabular}




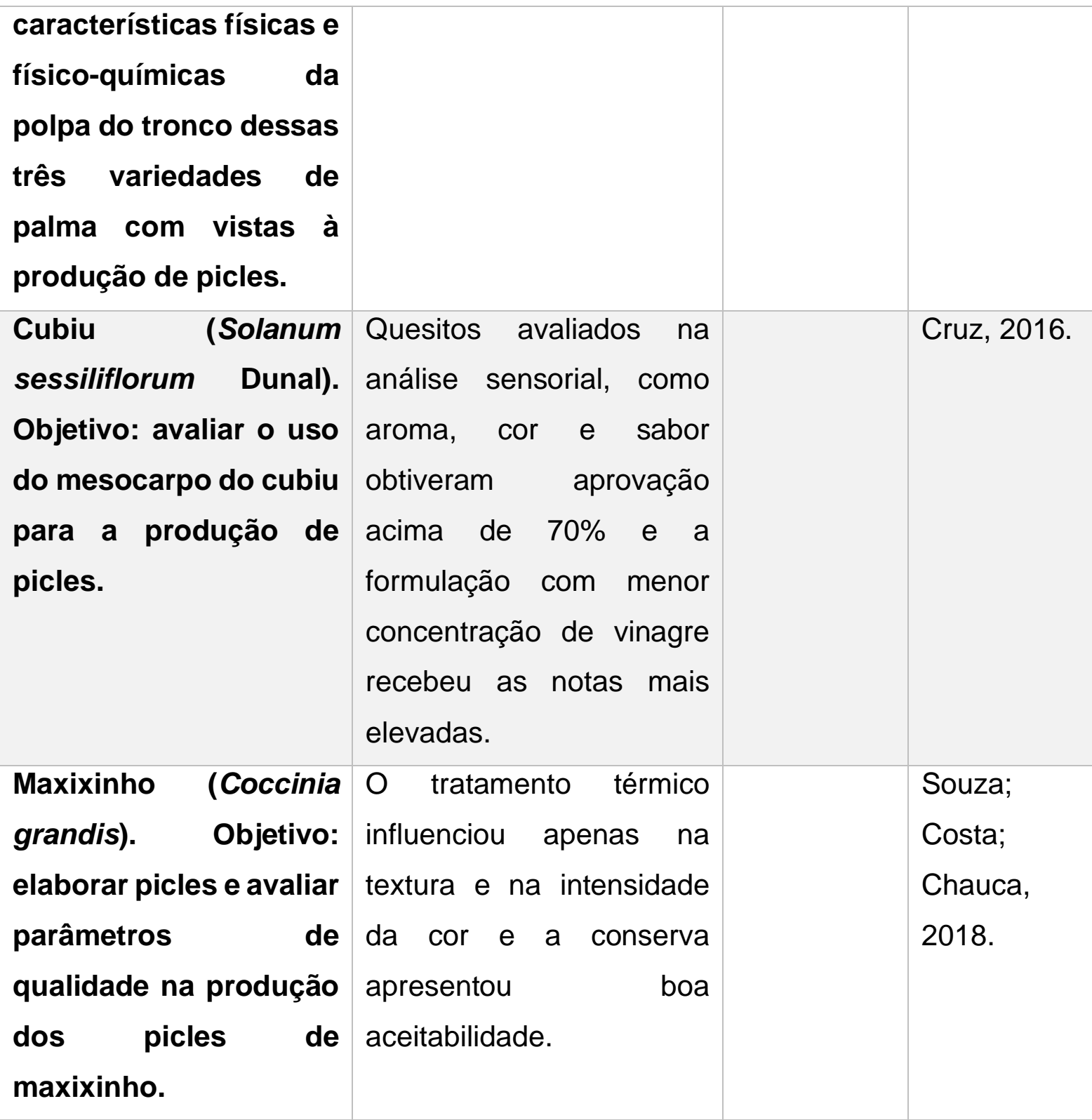

A Tabela 2 apresenta de forma resumida as motivações e dificuldades para a utilização de vegetais da flora brasileira na preparação de conservas ácidas (chutney) publicadas na literatura especializada.

Tabela 2 - Vegetais da flora brasileira utilizados na preparação de conservas ácidas (chutney).

\begin{tabular}{|l|l|l|l|}
\hline $\begin{array}{l}\text { Insumo utilizado na } \\
\text { produção de chutney }\end{array}$ & Motivações & Dificuldades & Referências \\
\hline
\end{tabular}




\begin{tabular}{|c|c|c|}
\hline $\begin{array}{l}\text { Cajarana } \\
\text { dulcis). } \\
\text { desenvolver picles e } \\
\text { chutney de cajaranas } \\
\text { frescas. }\end{array}$ & $\begin{array}{l}\text { Sensorialmente, os picles } \\
\text { e chutney de cajarana } \\
\text { foram bem aceitos. A cor, } \\
\text { sabor e textura foram } \\
\text { influenciadas pelo açúcar } \\
\text { para o chutney e pelo sal } \\
\text { para o picles. Ambos } \\
\text { contêm quantidades de } \\
\text { umidade e vitamina C } \\
\text { menores do que as frutas } \\
\text { frescas. Produtos estáveis } \\
\text { ao armazenamento. }\end{array}$ & $\begin{array}{l}\text { Bhuiyan, } \\
2012 .\end{array}$ \\
\hline $\begin{array}{l}\text { Maracujá do mato, ou } \\
\text { da caatinga (Passiflora } \\
\text { cincinnata Mast.) e } \\
\text { manga (Mangifera } \\
\text { indica L.). Objetivo: } \\
\text { presentar e descrever } \\
\text { o processamento do } \\
\text { chutney tendo como } \\
\text { ingredientes básicos o } \\
\text { maracujá da caatinga e } \\
\text { a manga. }\end{array}$ & $\begin{array}{l}\text { Devido à acidez do } \\
\text { maracujá do mato, não há } \\
\text { necessidade de se } \\
\text { adicionar vinagre. } \\
\text { chutney apresenta } \\
\text { coloração mais clara } \\
\text { quando açúcar orgânico é } \\
\text { utilizado. }\end{array}$ & $\begin{array}{l}\text { Torresan; } \\
\text { Silva; } \\
\text { Teixeira et } \\
\text { al., } 2015 \text {. }\end{array}$ \\
\hline 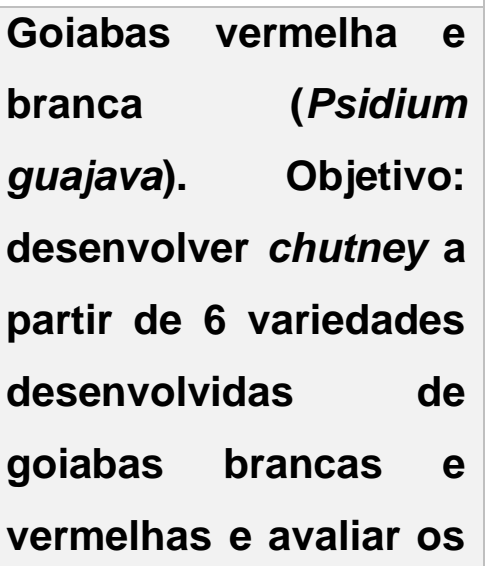 & $\begin{array}{l}\text { A inclusão de chutney de } \\
\text { goiabas na dieta diária } \\
\text { pode melhorar a qualidade } \\
\text { nutricional. }\end{array}$ & $\begin{array}{l}\text { Joshi; } \\
\text { Kochhar; } \\
\text { Boora, } 2017 .\end{array}$ \\
\hline
\end{tabular}


sensoriais

\section{e}

nutricionais.

Table 1 - Brazilian flora vegetables used in the preparation of pickles.

\begin{tabular}{|c|c|c|c|}
\hline $\begin{array}{l}\text { Inputs used in the } \\
\text { production of pickles }\end{array}$ & Motivations & Difficulties & References \\
\hline $\begin{array}{lr}\text { Green } & \text { beans } \\
\text { cowpea } & \text { [Vigna } \\
\text { unguiculata } & \text { (L.) } \\
\text { Walp.]. Objective: } \\
\text { to introduce } 10 \\
\text { strains and } 2 \\
\text { cultivars for } \\
\text { canned processing. }\end{array}$ & $\begin{array}{l}\text { Green cowpea beans } \\
\text { do not suffer major } \\
\text { changes and maintain } \\
\text { their good } \\
\text { characteristics in the } \\
\text { canned }\end{array}$ & $\begin{array}{l}\text { Partial loss of total } \\
\text { protein on grain. }\end{array}$ & $\begin{array}{l}\text { Lima; } \\
\text { Jerônimo; } \\
\text { Lima et al., } \\
2003 .\end{array}$ \\
\hline $\begin{array}{l}\text { Palm heart of the } \\
\text { 'punpunheira' } \\
\text { (Bactris gasipaes). } \\
\text { Objective: to } \\
\text { evaluate the effect } \\
\text { of three brines } \\
(3.5 \% \text {, } 4.0 \% \text { or } \\
4.5 \% \text { w/v, salt) on } \\
\text { the palate of } \\
\text { Pupunha palm } \\
\text { hearts for } \\
\text { application in the } \\
\text { agroindustry. }\end{array}$ & $\begin{array}{l}\text { Canned Punpunha } \\
\text { palm heart containing } \\
3.5 \% \text { or } 4.0 \% \text { brine in } \\
\text { salt had the preference } \\
\text { of the tasters for the } \\
\text { sensory attribute } \\
\text { "palmetto taste". For the } \\
\text { preservation of basal } \\
\text { palm, the tasters also } \\
\text { appreciated the palm of } \\
\text { the three brines. }\end{array}$ & & $\begin{array}{l}\text { Raupp; } \\
\text { Almeida; } \\
\text { Staron et } \\
\text { al., 2004. }\end{array}$ \\
\hline $\begin{array}{l}\text { Palm heart of the } \\
\text { 'punpunheira' (B. } \\
\text { gasipaes). }\end{array}$ & $\begin{array}{l}\text { Relatively high yield in } \\
\text { the production of } \\
\text { Punpunha palm heart, }\end{array}$ & $\begin{array}{l}\text { Variation in the } \mathrm{pH} \\
\text { of in natura hearts } \\
\text { palm is very }\end{array}$ & $\begin{array}{l}\text { Bellegard; } \\
\text { Raupp; }\end{array}$ \\
\hline
\end{tabular}




\begin{tabular}{|c|c|c|c|}
\hline $\begin{array}{l}\text { Objective: } \\
\text { evaluate to } \\
\text { efficiency of } 3 \\
\text { processing } \\
\text { acidification } \\
\text { procedures to } \\
\text { lower fresh palm } \\
\text { heart pH, which } \\
\text { should be equal to } \\
\text { or below 4.5. }\end{array}$ & $\begin{array}{l}\text { which can be } \\
\text { processed in various } \\
\text { ways. }\end{array}$ & $\begin{array}{l}\text { common. } \\
\text { Acidification at } \mathrm{pH}= \\
3.9 \text { is } \\
\text { recommended for } \\
\text { use in the palm } \\
\text { heart canning } \\
\text { agribusiness, } \\
\text { regardless of brine } \\
\text { chosen for the } \\
\text { conserves. }\end{array}$ & $\begin{array}{l}\text { Chaimsohn } \\
\text { et al., } 2005 . \\
\text { Gomes; } \\
\text { Valle; } \\
\text { Raupp et } \\
\text { al., 2006. }\end{array}$ \\
\hline $\begin{array}{lr}\text { Maxixe } & \text { (Cucumis } \\
\text { anguria } & \text { L.). } \\
\text { Objective: } & \text { to } \\
\text { present } & \text { an } \\
\text { alternative use of } \\
\text { this vegetable } \\
\text { through } \\
\text { fermentation for } \\
\text { pickle production. }\end{array}$ & $\begin{array}{l}\text { All the maxixe pickles } \\
\text { had a sensory } \\
\text { acceptance score of } 7 \\
\text { on the hedonic scale } \\
\text { (moderately liked) and } \\
60 \% \text { of the tasters } \\
\text { would certainly buy the } \\
\text { product. }\end{array}$ & & $\begin{array}{l}\text { Lima; } \\
\text { Trancoso; } \\
\text { Moura et al., } \\
2006 .\end{array}$ \\
\hline $\begin{array}{l}\text { Guariroba palm } \\
\text { heart [Syagrus } \\
\text { oleracea (Mart.) } \\
\text { Becc.] Objective: } \\
\text { to evaluate the } \\
\text { acceptance of } \\
\text { preserved } \\
\text { guariroba palm } \\
\text { hearts, acidified } \\
\text { with the organic } \\
\text { acids: acetic, citric, } \\
\text { d/-lactic } 85 \%, \mathrm{~d} / \text { - }\end{array}$ & $\begin{array}{l}\text { Acceptance greater } \\
\text { than } 80 \% \text { among } \\
\text { judges accustomed to } \\
\text { the consumption of } \\
\text { guariroba and greater } \\
\text { than } 65 \% \text { among non- } \\
\text { consumers. } \\
\text { Acidification costs of } \\
\text { canned with lactic, citric } \\
\text { and acetic acids were } \\
\text { equivalent to each other } \\
\text { and lower than those for }\end{array}$ & & $\begin{array}{l}\text { Jaime; } \\
\text { Moura; } \\
\text { Paula, } \\
2007 .\end{array}$ \\
\hline
\end{tabular}




\begin{tabular}{|c|c|c|c|}
\hline $\begin{array}{l}\text { malic and } \mathrm{L}(+)- \\
\text { tartaric. }\end{array}$ & $\begin{array}{l}\text { canned processed with } \\
\text { malic and tartaric acids. }\end{array}$ & & \\
\hline $\begin{array}{l}\text { Pinhão (Araucaria } \\
\text { angustifolia). } \\
\text { Objective: to } \\
\text { present the } \\
\text { preparation of } \\
\text { boiled and peeled } \\
\text { seeds in pickles. }\end{array}$ & $\begin{array}{l}\text { The cooked and peeled } \\
\text { pinhão seeds canned, } \\
\text { besides being a source } \\
\text { of starch, presented a } \\
\text { high content of dietary } \\
\text { fiber and low glycemic } \\
\text { index. Pinhão seeds } \\
\text { canned is already } \\
\text { commercialized in the } \\
\text { southern region of } \\
\text { Brazil. }\end{array}$ & & $\begin{array}{l}\text { Kinupp, } \\
2007 \text {, } \\
\text { 121-136. }\end{array}$ \\
\hline $\begin{array}{l}\text { Jurubeba-genunine } \\
\text { (Solanum } \\
\text { paniculatum L.). } \\
\text { Objective: to } \\
\text { present the } \\
\text { processing of fruits } \\
\text { in the form of } \\
\text { pickles. }\end{array}$ & $\begin{array}{l}\text { This plant is } \\
\text { widespread in all } \\
\text { Brazilian regions and, } \\
\text { for this reason, fruits of } \\
\text { Jurubeba-genuine are } \\
\text { widely marketed in } \\
\text { regional restaurants in } \\
\text { Goiás, Mato Grosso do } \\
\text { Sul and Minas Gerais, } \\
\text { both fresh and } \\
\text { conserved. }\end{array}$ & $\begin{array}{l}\text { There is no } \\
\text { bromatological } \\
\text { study on the fruits of } \\
\text { Jububeba-genuine. }\end{array}$ & $\begin{array}{l}\text { Kinupp, } \\
2007, \\
361-362 .\end{array}$ \\
\hline $\begin{array}{l}\text { Gherkins of purge } \\
\text { (Melothria } \\
\text { cucumis). } \\
\text { Objective: to make } \\
\text { sensory analysis of } \\
\text { fresh and }\end{array}$ & $\begin{array}{l}\text { Little purge gherkins } \\
\text { pickles had a mild flavor } \\
\text { when compared to the } \\
\text { conventional cucumber } \\
\text { (Cucumis sativus). } \\
\text { Crunchiness caused by } \\
\text { seeds during chewing. }\end{array}$ & $\begin{array}{l}\text { Acceptance smaller } \\
\text { than that the } \\
\text { marketed cucumber } \\
\text { (C. sativus). }\end{array}$ & $\begin{array}{l}\text { Kinupp, } \\
2007, \\
482-515 .\end{array}$ \\
\hline
\end{tabular}




\begin{tabular}{|c|c|c|c|}
\hline $\begin{array}{l}\text { preserved fruits of } \\
\text { this PANC. }\end{array}$ & & & \\
\hline $\begin{array}{l}\text { Inputs used in the } \\
\text { production of pickles }\end{array}$ & Motivations & Difficulties & References \\
\hline $\begin{array}{l}\text { Jerivá palm heart } \\
\text { (Syagrus } \\
\text { romanzoffiana). } \\
\text { Objective: to } \\
\text { characterize process of } \\
\text { production proce } \\
\text { palm heart of Jerivá } \\
\text { pickles and determine } \\
\text { the characteristics of } \\
\text { this product. }\end{array}$ & $\begin{array}{l}\text { Acidification procedure } \\
\text { designed for the } \\
\text { processing of palm } \\
\text { heart canned has been } \\
\text { shown to be efficient for } \\
\text { the production of safe } \\
\text { conserves, according to } \\
\text { the official standard, for } \\
\text { consumption in human } \\
\text { food. Pickles has an } \\
\text { astringent sensation } \\
\text { during its stay in the } \\
\text { mouth and was } \\
\text { therefore considered an } \\
\text { exotic product to be } \\
\text { consumed on special } \\
\text { occasions. }\end{array}$ & $\begin{array}{l}\text { Nutritionally, } \\
\text { pickled jerivá } \\
\text { heart of palm is } \\
\text { characterized } \\
\text { as a low } \\
\text { calories and } \\
\text { fibrous food. }\end{array}$ & $\begin{array}{l}\text { Raupp; } \\
\text { Kulchetski; } \\
\text { Bosmuler, } \\
2007 .\end{array}$ \\
\hline $\begin{array}{l}\text { Maxixe } \text { (Cucumis } \\
\text { anguria L.) } \\
\text { Objective: } \\
\text { to produce artificially } \\
\text { acidified preserves } \\
\text { and test chemical } \\
\text { stability and consumer } \\
\text { acceptance. }\end{array}$ & $\begin{array}{l}\text { It has pH values below } \\
4.5 \text {, so it can be } \\
\text { considered a safe } \\
\text { product for this } \\
\text { parameter. Sensorially it } \\
\text { is a well accepted } \\
\text { product. In addition, } \\
\text { pickled maxixe presents } \\
\text { market opening for }\end{array}$ & & $\begin{array}{l}\text { Nascimento; } \\
\text { Nunes; } \\
\text { Nunes, } \\
2011 .\end{array}$ \\
\hline
\end{tabular}




\begin{tabular}{|c|c|c|}
\hline & $\begin{array}{l}\text { industrial } \quad \text { scale } \\
\text { production. }\end{array}$ & \\
\hline 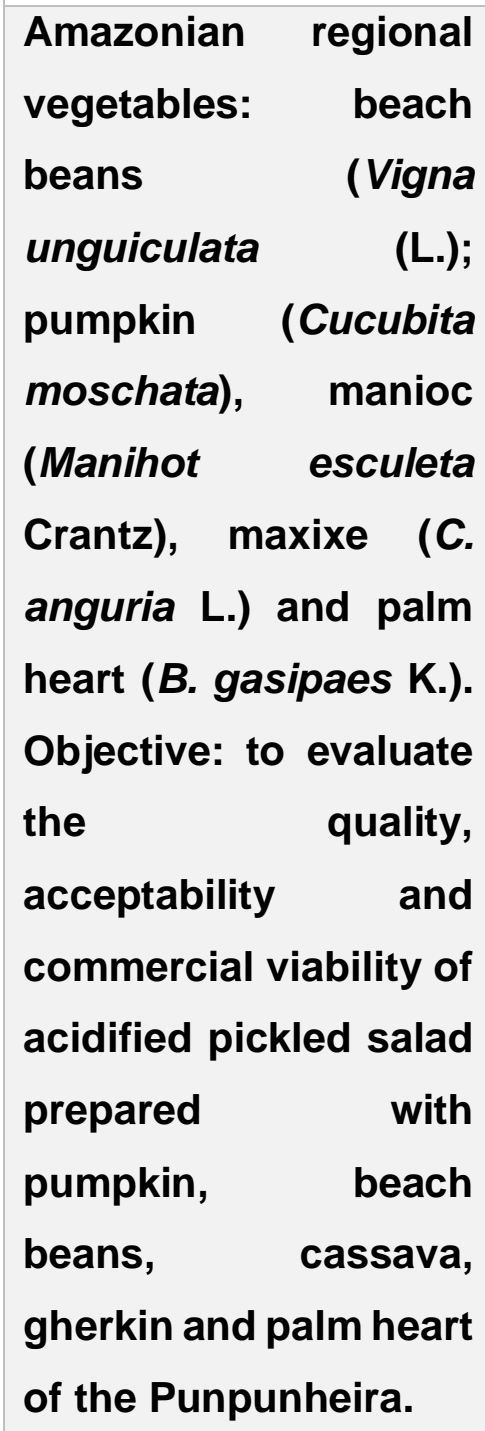 & $\begin{array}{l}\text { Product of low calorie } \\
\text { value, safe for } \\
\text { consumption and } \\
\text { without significant loss } \\
\text { of nutritional } \\
\text { constituents. Meets the } \\
\text { physicochemical and } \\
\text { microbiological } \\
\text { standards required by } \\
\text { Brazilian law. It } \\
\text { presented good } \\
\text { acceptance and sensory } \\
\text { quality variables similar } \\
\text { to those of the } \\
\text { industrialized and } \\
\text { nationally marketed } \\
\text { product. Product } \\
\text { obtained proved to be } \\
\text { competitive and } \\
\text { economically viable. }\end{array}$ & $\begin{array}{l}\text { Araújo; } \\
\text { Chaar; } \\
\text { Marques, } \\
2014 .\end{array}$ \\
\hline $\begin{array}{l}\text { "Sweet" (Nopalea } \\
\text { cochenilifera), } \\
\text { "round" (Opuntia sp) } \\
\text { and "big" (Opuntia } \\
\text { ficus indica Mill) palms } \\
\text { from the region of } \\
\text { Curimataú Paraibano. } \\
\text { Objective: to evaluate } \\
\text { the physical and }\end{array}$ & $\begin{array}{l}\text { Pickles produced from } \\
\text { pulp of the trunks of the } \\
\text { three palm varieties } \\
\text { presented evidence of a } \\
\text { high degree of } \\
\text { acceptance and } \\
\text { potential of their } \\
\text { commercialization in the } \\
\text { set of sensory analyzes. }\end{array}$ & $\begin{array}{l}\text { Morais } \\
\text { Júnior; } \\
\text { Laime; } \\
\text { Oliveira et } \\
\text { al., } 2014 \text {. }\end{array}$ \\
\hline
\end{tabular}




\begin{tabular}{|c|c|c|}
\hline $\begin{array}{l}\text { physicochemical } \\
\text { characteristics of the } \\
\text { trunk pulp of these } \\
\text { three palm varieties for } \\
\text { production of pickles. }\end{array}$ & & \\
\hline $\begin{array}{l}\text { Cubiu (Solanum } \\
\text { sessiliflorum Dunal). } \\
\text { Objective: to evaluate } \\
\text { the use of cubiu } \\
\text { mesocarp for pickle } \\
\text { production. }\end{array}$ & $\begin{array}{l}\text { Questions evaluated in } \\
\text { the sensory analysis, } \\
\text { such as smell, color and } \\
\text { taste obtained approval } \\
\text { above } 70 \% \text { and } \\
\text { formulation with the } \\
\text { lowest vinegar } \\
\text { concentration received } \\
\text { the highest grades. }\end{array}$ & Cruz, 2016. \\
\hline $\begin{array}{l}\text { Maxixinho (Coccinia } \\
\text { grandis). Objective: to } \\
\text { prepare pickles and to } \\
\text { evaluate quality } \\
\text { parameters in the } \\
\text { production of } \\
\text { maxixinho pickles. }\end{array}$ & $\begin{array}{l}\text { Heat treatment } \\
\text { influenced only the } \\
\text { texture and color } \\
\text { intensity and the pickles } \\
\text { presented good } \\
\text { acceptability. }\end{array}$ & $\begin{array}{l}\text { Souza; } \\
\text { Costa; } \\
\text { Chauca, } \\
2018 .\end{array}$ \\
\hline
\end{tabular}

Table 2 - Brazilian flora vegetables used in the preparation of chutney.

\begin{tabular}{|l|l|l|l|}
\hline $\begin{array}{l}\text { Inputs used in the } \\
\text { production of chutney }\end{array}$ & Motivations & Difficulties & References \\
\hline $\begin{array}{l}\text { Cajarana (Spondias } \\
\text { dulcis). Objective: to }\end{array}$ & $\begin{array}{l}\text { Sensorially, the Cajarana } \\
\text { pickles and chutney were }\end{array}$ & Bhuiyan, \\
$\begin{array}{l}\text { develop pickles and } \\
\text { chutney from fresh } \\
\text { Cajaranas. }\end{array}$ & $\begin{array}{l}\text { flavor and texture were } \\
\text { influenced by sugar for } \\
\text { chutney and salt for pickles. }\end{array}$ & \\
\end{tabular}




\begin{tabular}{|c|c|c|}
\hline & $\begin{array}{l}\text { Both contain lower amounts } \\
\text { of moisture and vitamin C } \\
\text { than fresh fruits. Storage } \\
\text { stable products. }\end{array}$ & \\
\hline $\begin{array}{l}\text { Caatinga's passion fruit } \\
\text { (Passiflora cincinnata } \\
\text { Mast.) and mango } \\
\text { (Mangifera indica L.). } \\
\text { Objective: to present } \\
\text { and describe the } \\
\text { processing of chutney } \\
\text { with Caatinga's } \\
\text { passion fruit and } \\
\text { mango. }\end{array}$ & $\begin{array}{l}\text { Due to the acidity of the } \\
\text { Caatinga's passion fruit, } \\
\text { there is no need to add } \\
\text { vinegar. Chutney is lighter in } \\
\text { color when organic sugar is } \\
\text { used. }\end{array}$ & $\begin{array}{l}\text { Torresan; } \\
\text { Silva; } \\
\text { Teixeira et } \\
\text { al., } 2015 \text {. }\end{array}$ \\
\hline $\begin{array}{l}\text { Red and white guavas } \\
\text { (Psidium guajava). } \\
\text { Objective: to develop } \\
\text { chutney from } 6 \\
\text { developed varieties of } \\
\text { white and red guavas } \\
\text { and evaluate their } \\
\text { sensory and nutritional } \\
\text { attributes. }\end{array}$ & $\begin{array}{l}\text { Including guava chutney in } \\
\text { the daily diet can improve } \\
\text { nutritional. }\end{array}$ & $\begin{array}{l}\text { Joshi; } \\
\text { Kochhar; } \\
\text { Boora, } 2017 .\end{array}$ \\
\hline
\end{tabular}

\section{CONSIDERAÇÕES FINAIS}

Os dados obtidos por meio da pesquisa bibliográfica sobre a utilização de vegetais e frutas da flora brasileira como insumos para preparação de conservas em salmoura (picles) ou ácidas (chutney) indicam uma grande variabilidade regional, haja visto que nos artigos publicados foram utilizados vegetais e frutas cultivados nas cinco regiões brasileiras, porém a preparação das conservas a partir dos insumos carecem de aperfeiçoamento na produção e na perda de atributos nutricionais e/ou sensoriais. 
Portanto, isto dá uma ideia de que nem sempre a possibilidade viável de conservação sob as formas artesanal ou industrial, de um vegetal oriundo de um determinado bioma não implica que o mesmo terá aceitação total dos consumidores.

\section{REFERÊNCIAS}

ARAÚJO, Elizalane M.; CHAAR, José M.; MARQUES, Jean D. de O. Salada em conserva elaborada com hortaliças regionais amazônicas. Revista Brasileira de Engenharia Agrícola e Ambiental, Campina Grande, v.18, n.5, p.527-532, 2014.

BARCELOS, Maria de Fátima Píccolo; TAVARES, Débora de Queiroz; SILVA, Maria Aparecida A. P.; et al. Aspectos tecnológicos e sensoriais do guandu [Cajanus cajan (L.) Mill sp.] enlatado em diferentes estádios de maturação. Ciência e Tecnologia de Alimentos, Campinas, v .19, n. 1, p. 73-83, 1999.

BELLEGARD, Claudio Roberto Gomes; RAUPP, Dorivaldo da Silva; CHAIMSOHN, Francisco Paulo; et al. Avaliação de procedimentos de acidificação de conservas de palmito foliar de pupunha (Bactris gasipaes). Acta Scientiae Agronomica, Maringá, v. 27, n. 2, p. 247-254, 2005.

BENEVIDES, Clícia Maria de Jesus; FURTUNATO, Dalva Maria da Nóbrega. Hortaliças Acidificadas. Ciência e Tecnologia de Alimentos, Campinas, v. 18, n. 3, p. 1-7, 1998.

BERBARI, Shirley Aparecida Garcia; PRATI, Patrícia; JUNQUEIRA, Valéria Christina Amstalden. Qualidade do palmito da palmeira real em conserva. Ciência e Tecnologia de Alimentos, Campinas, v. 28, n. supl., p. 135-141, 2008.

BHUIYAN, Mohamed Hafizur Rahman. Pickle and chutney development from fresh hog plum (Spondias dulcis). Journal of Environment and Sciences \& Natural Resources, v. 5, n. 2, p. 67-72, 2012.

BRASIL. Agência Nacional de Vigilância Sanitária. ANVISA. RDC. n. 272, de 22 de setembro de 2005. Regulamento técnico para produtos de vegetais, produtos de frutos 
e cogumelos comestíveis. Diário Oficial da União, Poder Executivo, Brasília, DF. Disponível em:

http://bvsms.saude.gov.br/bvs/saudelegis/anvisa/2005/rdc0272_22_09_2005.html Acesso em: 11/08/2019.

BROWN, Linda. O Livro das Conservas: deliciosas receitas de compotas, geleias, chutneys e picles. Traduzido por: Marina Petroff Garcia. São Paulo: Publifolha, 2012, $352 \mathrm{p}$.

CARVALHO, Nilson Luiz de Aguiar; LESSI, Edson. Elaboração de uma semiconserva de pescado de água doce "picles de peixe". I - Tempo de cura, acidificação, textura e nível de sal. Acta Amazônica, Manaus, v. 20 (único), p. 321-329, 1990.

CAVALCANTI, Nilton de Brito; SANTOS, Carlos Alberto Fernandes; REZENDE, Geraldo Milanez et al. Produção de picles com o xilopódio de Spondias tuberosa e teste de aceitação. Agrotrópica, llhéus, v. 13, n. 2, p. 43-48. 2001.

CRUZ, Raydson Pires da. Processamento, características físico-químicas e sensoriais de picles de Cubiu (Solanum sessiliflorum Dunal). 2016. 61f. Dissertação (Mestrado em Agricultura no Trópico Úmido) - Instituto Nacional de Pesquisas da Amazônia INPA, Manaus, AM, 2016.

FRANCO, Ariovaldo. De caçador a gourmet: uma história da gastronomia. São Paulo: Editora Senac São Paulo, 2001, 350 p.

GOLDONI, José Santo et al. Estudo da produção de chucrute do repolho "Matsukase" em diferentes estágios de maturação: sólidos solúveis, $\mathrm{pH}$, acidez total e tempo de fermentação. Boletim da Sociedade Brasileira de Ciência e Tecnologia de Alimentos, Campinas, v.16, n. 2, abr/jun., 1988.

GOMES, Marcelo; VALLE, Janaina do; RAUPP, Dorivaldo da Silva; et al. Processamento de conservas de palmito caulinar de pupunha contendo diferentes graus de acidez. Ciência Agrotécnica, Lavras, v. 30, n. 3, p. 569-574, 2006. 
JAIME, Nilson Gomres; MOURA Celso José; PAULA, Ydilla Oliveira de. Aceitação do palmito de guariroba [Syagrus oleracea (Mart.) Becc.] em conservas sob diferentes ácidos orgânicos. Pesquisa Agropecuária Tropical, v. 37, n. 4, p. 257-266, 2007.

JOSHI, Homi; KOCHHAR, A.; BOORA, R. S. Development and Quality Evaluation of Chutney from New Varieties of White and Pink-Fleshed Guava. International Journal of Current Microbiology and Applied Sciences, v. 6, n. 10, p. 1062-1068, 2017.

KINUPP, Valdely Ferreira. Plantas Alimentícias Não-Convencionais da Região Metropolitana de Porto Alegre, RS. 2007. 590f. Tese (Doutorado em Fitotecnia) Faculdade de Agronomia - Universidade Federal do Rio Grande do Sul - UFRGS, Porto Alegre, RS, 2007.

KURLANSKY, Mark. Sal: uma história do mundo. Tradução de Silvana Vieira. São Paulo: Editora Senac São Paulo, 2003. 320 p.

LIMA, Álvaro Silva; TRANCOSO, Francielli Oliveira; MOURA, Karla Macedo; et al. Caracterização centesimal de maxixe e sua aplicação na produção de picles. Alimentos e Nutrição, Araraquara, v. 17, n. 4, p. 407-412, 2006.

LIMA, Eliza D. P. de Andrade; JERÔNIMO, Edlene de S.; LIMA, Carlos Alberto de A.; et al. Características físicas e químicas de grãos verdes de linhagens e cultivares de feijão caupi para processamento tipo conserva. Revista Brasileira de Engenharia Agrícola e Ambiental, Campina Grande, v. 7, n. 1, p.129-134, 2003.

MORAIS JÚNIOR, Ricardo César de; LAIME, Eduardo Maciel Oliveira; OLIVEIRA, Dayane Cristine de Souza; et al. Caracterização e aceitabilidade do picles do tronco de palma. Engenharia Ambiental, Espírito Santo do Pinhal, v. 11, n. 2, p. 17-27, 2014.

NASCIMENTO, Afra Maria do Carmo Bandeira; NUNES, Regiane Gonçalves Feitosa Leal; NUNES, Luís Alfredo Pinheiro Leal. Elaboração e avaliação química, biológica e sensorial de conserva de maxixe (Cucumis anguria L.). Acta Tecnológica, v. 6, n. 1, p. 123-136, 2011. 
PIZZATTO, Mariana; LUCKMANN, Daiane; MOURA, Cláudia de Andrade; et al. Avaliação sensorial de raízes de rabanete (Raphanus sativus L.) minimamente processadas em forma de picles. In: Congresso de Ciência e Tecnologia da UTFPR, 1. 2011, campus Dois Vizinhos-PR, 2011. Disponível em: $<$ http://revistas.utfpr.edu.br/dv/index.php/CCT_DV/article/view/670>. Acesso em: 11/08/2019. p. 111-114.

RAUPP, Dorivaldo da Silva; KULCHETSKI, L.; BOSMULER, L. C. Processamento de palmito Jerivá (Syagrus romanzoffiana) em conserva. Revista Tecnológica, v. 16, p. 75-82, 2007.

RAUPP, Dorivaldo da Silva; ALMEIDA, Flávia Caroline Costa; STARON, Enelise Aparecida; et al. Conservas de palmito de pupunha em diferentes salmouras Avaliação Sensorial. PUBLICATIO UEPG Ciências Exatas e da Terra, Ciências Agrárias e Engenharias, Ponta Grossa, v. 10, n. 1, p. 27-33, 2004.

RIBEIRO, Ana Teresa; RAIMUNDO, António; LARANJEIRA, Cristina; et al. Desenvolvimento de diferentes formulações de chutney. Revista da Unidade de Investigação do Instituto Politécnico de Santarém, v. 2, p. 164-176, 2013. Disponível em: <http://hdl.handle.net/10400.15/844>. Acesso em: 11/08/2019.

SEBESS, Mariana. Técnicas de cozinha profissional. 3. ed. rev. e ampliada, 4. reimpressão. Tradução de: Helena Londres. Rio de Janeiro: Senac Nacional, 2014, $360 \mathrm{p}$.

SOUZA, Thaís Inês M.; COSTA, Cândido A.; CHAUCA, Milton N. C. Influence of the heat treatment on the quality of ivy gourd (Coccinia grandis). Horticultura Brasileira, v. 36 , p. 126-129, 2018.

TORRESAN, Renata; SILVA, Bianca Souza Góes da; TEIXEIRA, Nátali Silva; et al. Processamento de molho "chutney" composto de maracujá da Caatinga e manga. Comunicado Técnico da Embrapa, n. 213, p. 1-3, dez, 2015.

Enviado: Setembro, 2019. 
Aprovado: Outubro, 2019. 